reference care of worried and "difficult" patients and the handling of particular problems such as the social and psychological management of terminal cases, we need the services of trained social workers whose job is primarily personal contact with the patient. We should value the essential and excellent help that they can give in overall patient care when encouraged in this function by members of the medical profession who do not find their presence threatening. -We are, etc.,

Department of Psychiatry,

Birmingham

Gillian STRATFORD

Department of Social Medicine,

Medical School

Birmingham

\section{Intracranial Venous Thrombosis and the Pill}

SIR,-I was surprised to see only the progestogen component of two oral contraceptives mentioned in an article on cerebral thrombosis attributed to their use (16 June, p. 647).

Both contraceptive pills contain oestrogen as well: mestranol $\mathbf{0 . 1} \mathbf{~ m g}$ in Ortho-Novin, and ethinyloestradiol $0.05 \mathrm{mg}$ in Minovlar. So far as I know, no episodes of thrombosis have been reported as due to progestogenonly contraceptives. On the other hand, oestrogens are known to affect several blood clotting factors, and the increased incidence of thromboembolic disease in women taking combined preparations is accented as due to the oestrogen component.-I am, etc.

Kempsey, N.S.w.

P. N. Holberton Australia

\section{Smoking Hazards to the Fetus}

SIR,-Space does not permit a full analysis of the letter from Dr. R. T. Hickey and his colleagues (1 September, p. 501) in which they discuss the role of possible causative factors influencing the well-known statistical association between maternal cigarette smoking in pregnancy and birth weight.

We are concerned, however, that they cite our work $^{1}$ only to dismiss it as in "error." We did not, in fact, make the elementary error of suggesting that an association by itself proves a causal relationship; nor, so far as we are aware, do other reports in the literature. We did in fact suggest that it might be possible to test the causal hypothesis by a controlled trial in which women were persuaded to give up smoking during pregnancy.

Dr. Hickey and his colleagues appear to dismiss a causal relationshio because not all babies of smokers are of low birth weight. Is this really what they imply? The "alternative" hypothesis which Yerushalmy ${ }^{2}$ is purported to have tested (namely, that babies born to women before they become smokers will be lighter than those of non-smokers) suffers from severe methodological shortcomings, ${ }^{3}$ making it clearly untenable. We would, however, agree with them that the "causal" question is still not settled, but we feel that it would be unfortunate if the progress so far made in discouraging mothers from smoking in pregnancy were to be inter-

rupted by the kind of arguments used in their letter.-We are, etc.,

EUAN M. ROSS Department of Child Health, Royal Hospital for Sick Children,

National Children's Bureau N. R. BUTLER London W.1

1 Butler, N. R., Goldstein, H., and Ross, E. M., British Medical foumal, 1972, 2, 127 Yerushalmy, J., American Journal of Obstetrics and Gynecology, 1972, 112, 277 Goldstein, H., American fourmal of Obstetrics

\title{
H. GoldsteIN
}

office bearers who are coloured as well as white; and (3) that the Municipality of Johannesburg has this year decided that it will no longer continue the differentiation of its large municipal staff and has levelled up salaries with no racial discrimination.

It is thus to be hoped that the weight of public as well as professional opinion may yet bring about a change while the Nationalist government continues in power.-I am, etc.,

Delgany,
Co. Wicklow, Eire

HugH WOODMaN

\section{Doctors in South Africa}

SiR,-Apparently Mr. I. N. Bernadt (22 September, p. 632) reads only the advertisement pages of the South African Medical fournal, otherwise he would know that the Medical Association of South Africa has done considerably more than utter verbal condemnation of racial discrimination in the medical field. It has repeatedly serit deputations to the Minister of Health requesting abolition of discrimination in salaries, resulting at one stage in an (admittedly only slight) improvement. Over a year. ago in its journal it publicized the establishment of a Salary Equalization Fund for the receipt of voluntary contributions from non-African doctors towards supplementing the official salaries of their African colleagues. (I hope the fund will receive many contributions as a result of Dr. Bernadt's and this letter.)

The fact that coloured doctors cannot, in South Africa, examine white patients is not due to the attitude of the medical profession in that country or even to the Government, as Dr. Bernadt surely must know. With rare exceptions, white persons would refuse - generally with vehemence-to be examined by non-white doctors; and even if they agreed, white nurses in attendance upon them would refuse to assist in such examinations, generally with no less vehemence and with the support of every member of parliament (government and opposition), except perhaps one, the vast majority of their white nursing colleagues, and South African Whites as a whole. These attitudes of white patients and nurses long antedate 1948, the year in which the present political rulers of South Africa came first to power.-I am, etc.,

Surbiton, Surrey

G. W. GALE

SIR,-Anyone with knowledge of the practice of medicine in South Africa will be acquainted with the injustice of the two salary scales for doctors and nurses, based on colour, to which Dr. I. N. Bernadt refers in his letter (22 September, p. 632). Over the years there have been demonstrations, protests, even resignations over this question, and agitation mounts in the press and elsewhere against this system.

Apartheid remains dominant politically but it may be noted (1) that the South African Medical and Dental Council, equivalent to the G.M.C. at home, registers doctors in alphabetical order with no reference to colour or recognition or apartheid, all on the register having equal voting rights; (2) that the Medical Association of South Africa has similarly maintained this attitude and has

\section{Alcoholism and the G.P.}

SIR,-In view of the considerable publicity and controversy associated with the "Helping Hand" report on this matter ${ }^{1}$ I would be grateful for an opportunity to identify my position. In the lecture of mine quoted in the report I said, "Studies suggest the general practitioner is frequently not an effective agent for picking up alcoholics. The reasons would anpear to be two-fold. Firstly, the patient or the patient's relatives are unwilling to bring this problem to the doctor. Secondly, the general practitioner is likely to miss cases of alcoholism if his stereotype of the alcoholic is of a skid row figure-that is, the end state of the disease becomes the only form recognized and his lack of awareness that in the early stages alcoholism presents with primarily social, rather than medical pathology."

Unfortunately in the majority of press reports only the second reason was quoted, suggesting that I was unaware of the great difficulty the general practitioner has in dealing with patients who deny their problem. I am of course fully aware of this and had no intention of criticizing general practitioners at large in relation to their difficulty in identifying the alcoholic. I was trying to emphasize the importance of early detection and how alcoholism will often present to a doctor in social rather than medical terms. In any comprehensive treatment service for alcoholics the general practitioner has a major role in diagnosis, and it is hoped that the recent upsurge in interest among general practitioners in the last two years, as evidenced by requests for postgraduate lectures, articles in journals, and research studies, will be maintained.-I am, etc.,

Alcoholic Treatment Unit, Springfield Hospital,
Manchester

B. D. HORE

Alcoholism and the G.P. London, Helping Hand Organisation, 1973

Shake Test on Amniotic Fluid and the Respiratory Distress Syndrome

SIR,-I wish to comment on the suggestion of Dr. P. M. Fisher and others (19 May, p. 423) that, for assessing fetopulmonary maturity and the risk of neonatal respiratory distress syndrome, a critical amniotic fluid lecithin concentration of $3.5 \mathrm{mg} / 100 \mathrm{ml}$ is too low. Their suggestion is based on the evidence of pulmonary hypoperfusion in two newborn infants with predelivery amniotic fluid lecithin levels of 5.70 and $7.35 \mathrm{mg} / 100$ $\mathrm{ml}$ respectively and a negative bubble stability test though the infants had no respira- 